\title{
Effects of Nigella sativa (Kalonji) and Honey on Lipid Profile of Hyper lipidemic Smokers
}

\author{
Inayatullah Bhatti ${ }^{1}$, Saira Inayat ${ }^{2}$, Bushra Uzair ${ }^{3}$, Farid Menaa ${ }^{4}$, Sattar Bakhsh ${ }^{1}$, Haroon Khan ${ }^{1}$, Falak \\ Naz $^{1}$, Barkat Ali Khan ${ }^{1 *}$
}

${ }^{1}$ Faculty of Pharmacy, Gomal University, Dera Ismail Khan 29500, Khyber Pakhtunkhwa, PAKISTAN. 2Department of Biological Sciences, Gomal University, Khan 29500, Khyber Pakhtunkhwa, PAKISTAN. ${ }^{3}$ Department of Bioinformatics \& Biotechnology, International Islamic University, Islamabad, PAKISTAN. ${ }^{4}$ Department of Pharmaceutical Sciences and Nanomedicine, Fluorotronics Inc., San Diego, CA, USA.

\begin{abstract}
Background: Hyper lipidemia refers to the excess of lipids in the blood of patients. The present study was carried out to investigate the effect of Nigella sativa (kalonji) and honey as compared with Atorvastatin on the lipid profile of hyper lipidemia patients with habit of smoking. Methodology: Purposes, 60 patients (3 groups of 20) of 35-65 years were selected. These patients were treated with $1 \mathrm{~g}$ of Nigella sativa (kalonji) seed, one tablespoon of honey, and Atorvastatin $10 \mathrm{mg}$ daily in the morning at fasting for a period of 30 days. Results: The results obtained showed that Nigella sativa (kalonji), honey as well as Atorvastatin lowered significantly the levels of total cholesterol (TC), low density lipoproteins (LDL) and triglycerides (TGs) after 30 days of treatment. On the other hand, all the treatments increased HDL levels significantly after 30 days treatments were non-significant on TC and LDL levels of smokers. But after 30 days of treatment, Atorvastatin was significantly more effective than honey and Nigella sativa (kalonji). Honey reduced TGs level of smokers significantly over Nigella sativa (kalonji) and Atorvastatin. Conclusion: It can be concluded that both Nigella sativa (kalonji) and honey were as effective as Atorvastatin or more effective in some cases in reducing TC, LDL and TGs of hyper lipidemic smokers significantly while HDL levels were increased significantly.
\end{abstract}

Key words: Alternative and Complementary Medicine, Atorvastatin, Honey, Hyper lipidemia, Smoking, Kalonji, Preventive Medicine, Smoking.

\section{INTRODUCTION}

Hyper lipidemia is a heterogeneous group of disorders characterized by an excess of lipids in the bloodstream. These lipids include cholesterol, cholesterol esters, phospholipids, and triglycerides. Lipids are transported in the blood as large 'lipoproteins'. Familial combined hypercholesterolemia is the most common primary lipid disorder, characterized by moderate elevation of plasma triglycerides and cholesterol and reduced plasma highdensity lipoproteins (HDL-C).

Dietary causes of byper lipidemia include fat intake per total calories greater than $40 \%$; saturated fat intake per total calories greater than $10 \%$; cholesterol intake greater than $300 \mathrm{mg}$ per day; and habitual excessive alcohol use. Lifestyle contributing factors include smoking, obesity and lack of exercise. As regards prevalence of byper lipidemia, many surveys have been made in Pakistan. ${ }^{1}$ made a cross-sectional study to determine the frequency of byper lipidemia in patients presenting with ischemic stroke in Multan, Pakistan. They reported that frequency of byper lipidemia was $37.1 \%$ in patients with ischemic stroke, in a sample of 178 individuals. ${ }^{2}$ reported that prevalence of byper lipidemia, high cholesterol and diabetes.
Submission Date : 02-01-2016 Revision Date : :29-02-2016 Accepted Date : :12-03-2016

DOI: 10.5530/ijper.50.3.9 Correspondence:

Dr. Barkat Ali Khan Department of Pharmaceutics, Faculty of Pharmacy, Gomal University, Dera Ismail Khan 29050, Khyber Pakhtunkhwa, PAKISTAN.

Mob No: $+92-333-9732578$

Phone/Fax: $+92-966-750284$ Email:barki.gold@gmail.com

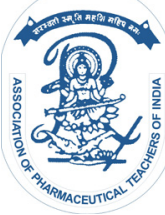

www.ijper.org 
In the lower middle class residing in urban localities of Karachi, Pakistan were 38.5, 10.7 and 9.1\%, respectively, $52.2 \%$ of the sample was obese or over-weight, $11.9 \%$ had two or more major risk factors of CHD.

Numerous traditional applications of Nigella sativa seeds were recorded as medicinal and pharmacological activities It has been reported that cholesterol decreased by $(-14.58 \%)$, LDL (-23.00\%), and triglycerides (-15.16\%) significantly after treatment with kalonji, whereas there was a significant increase in HDL (3.18\%) after six months. It has also been showen in an experiment on rats that Nigella sativa (kalonji) had significantly affected the lipid profile as compared to control. There was $70 \%$ and $25.3 \%$ reduction in LDL and TGs levels, respectively, and $53.5 \%$ increase in HDL levels of rats. Similarly it is also showed significant decrease in serum LDL level and increase in HDL levels by kalonji treatment on rats.-9

Honey has had a valued place in traditional medicine for centuries. Some researchers reported potential protective effects of prolonged preconditioning with natural honey against myocardial infarction in rats. ${ }^{13}$ reported that levels of LDL and TGs decreased in rats which were given acacia honey and reached near towards normal level. ${ }^{10-14}$

\section{MATERIALS AND METHODS}

The present study was planned to evaluate the effects of Nigella sativa (kalonji) seed and honey on the lipid profile of hyper lipidemic patients with smoking habit in comparison with a standard drug Atorvastatin at the Department of Pharmacology, Faculty of Pharmacy, Gomal University Dera Ismail Khan (D.I. Khan) Pakistan. This study was carried out in cardiac unit of District Head Quarter Teaching Hospital D.I. Khan.

Seeds of Nigella sativa (kalongi) were purchased from the local market of Dera Ismail Khan and material was identified by a botanist Dr. Surfraz Khan Marwat, Associate Professor in Gomal University, Dera Ismail Khan. $500 \mathrm{~g}$ of dried plant material was cleaned from dust and coarsely grounded; 2 gm of this cleaned and coarsely grounded material was filled in hard gelatin capsules. Each patient was advised to take one capsule of kalonji on empty stomach for one month. Honey was also obtained from the local market.

\section{Selection of Patients}

For the selection of the subjects, stratified random design of sampling was used. ${ }^{15}$ Sixty male patients of hyper lipidemic patients with habits of smoking of 35-65 years age were selected. 3 groups of twenty patients each were assigned to one of the three treatments, namely kalonji, honey or Atorvastatin.

\section{Treatments}

Three treatments were tried in this trial. All the 20 patients were given $2 \mathrm{~g}$ Nigella sativa seed powder in capsules per day at fasting for 30 days. One table spoonful of honey per day at fasting was administered to the other 20 parents. For the purpose of comparison, a standard drug Atorvastatin was also used. Atorvastatin at the rate of $10 \mathrm{mg} /$ day was given to the other 20 patients at fasting. Duration of treatment for all the three different treatments was 30 days.

\section{Blood Sampling}

Patients of all the three groups treated with all the three treatments were sampled for blood at fasting. Blood sampling was done three times during the study. First sampling was done before treatment, second sampling after 15 days of treatment, and the third sampling was done after 30 days of treatment.

\section{Chemical Analysis}

Blood samples of all the patients collected before treatment as well as after 15 and 30 days of treatment after 15 and 30 days of treatment were subjected for measurement of total cholesterol, low density lipoproteins (LDL), high density lipoproteins (HDL) and triglycerides using commercial kits (Roche, Germany).

\section{Statistical Analysis}

Statistical analysis of the data collected during this study was undertaken according to the procedures given by. ${ }^{16}$ Paired t-test was used to compare between means of various blood parameters before and after treatment. Regression analysis was used to quantify changes in various blood parameters with duration of treatment. Completely Randomized Design (CRD) analysis of variance (ANOVA) was run for testing the significance of treatments for various blood parameters. Least Significant Test (LSD) of significance was used to compare the means of different treatments; $\mathrm{P}<0.05$ was considered as significant statistically.

\section{RESULTS}

This piece of research was carried out to study the effect of Nigella sativa(kalongi) and honey along with a standard (Atorvastatin) on the lipid profiles of male individuals with smoking habit.

\section{Effects of kalonji on lipid profiles of smokers}

The effects of kalongi on the lipid profile of male smokers have been summarized in Table 1. The results 
(Table 1) showed that the total cholesterol (TC) level of smokers before treatment with kalonji ranged from 213 to 299 with a mean value of $259.50 \mathrm{mg} / \mathrm{dL}$ and a coefficient of variation of $10.13 \%$. Fifteen days after treatment with kalonji, the total cholesterol (TC) level of smokers was reduced and it ranged from 190 to 266 with a mean value of $228.50 \mathrm{mg} / \mathrm{dL}$ and a coefficient of variation of $11.75 \%$. After 30 days of treatment with kalonji, total cholesterol level ranged from 167 to 244 with a mean value of $206.75 \mathrm{mg} / \mathrm{dL}$ and a coefficient of variation of $12.31 \%$.

By comparing the total cholesterol level of smokers before and after treatment using t-test of significance, it was found that the cholesterol level was significantly reduced after 15 days of treatment (259.50a vs 228.50b, t.01 $=37.18$ ) by $12 \%$. It was further significantly reduced $(228.50 \mathrm{a}$ vs $206.15 \mathrm{~b}$, t.01 $=20.76)$ after 30 days of treatment as compared with 15 days after treatment. However, the total reduction in total cholesterol level of smokers after 30 days of treatment was $21 \%$ as compared with the level before treatment.

\section{Low Density Lipoproteins (LDL)}

Data collected on LDL level of smokers before and after treatment with kalonji (Table 1) showed that before treatment, it ranged from 210 to 271 with a mean value of $252.50 \mathrm{mg} / \mathrm{dL}$ and a coefficient of variation of $6.32 \%$. LDL level of smokers 15 days after treatment with kalonji ranged from 188 to 251 with a mean value of $252.50 \mathrm{mg} / \mathrm{dL}$ and a coefficient of variation of $7.26 \%$. It ranged from 165 to 234 with a mean value of 208.80 $\mathrm{mg} / \mathrm{dL}$ and a coefficient of variation of $9.07 \%$ thirty days after treatment with kalonji. Comparing the LDL levels of smokers before and after treatment with kalonji, it can be observed that the LDL decreased consistently 15 days after treatment and 30 days after treatment. The decrease in LDL levels 15 days after treatment was significant $(252.50$ a vs $229.35 \mathrm{~b}, \mathrm{t} .01=24.49)$ and the decrease was about $9 \%$. Comparing the LDL levels 15 days after treatment and 30 days after treatment, there was a further significant decrease in LDL level (229.35 a vs $208.80 \mathrm{~b}, \mathrm{t} .01=-22.29)$. However, the total decrease in the LDL level 30 days after treatment with kalonji was about $27 \%$.

\section{High Density Lipoproteins ( $H D L)$}

Data collected on HDL level of smokers as influenced by kalonji (Table 1) showed that it ranged from 28 to 33 with a mean value of $30.75 \mathrm{mg} / \mathrm{dL}$ and a CV of $5.04 \%$ showing low variability in the data before treatment. Fifteen days after treatment with kalonji, the HDL of smokers increased and the range was from 33 to 39 with a mean value of $36.25 \mathrm{mg} / \mathrm{dL}$ and a CV of $4.63 \%$. In case of treatment for 30 days, the HDL level further increased and the range was from 37 to 41 with a mean value of $39.05 \mathrm{mg} / \mathrm{dL}$ and a very low CV of $2.82 \%$.

Comparing the mean values of HDL of smokers before and after treatment with kalonji, it was observed that the HDL increased significantly over HDL level before treatment after 15 days of treatment (30.75).

\section{Triglycerides (TGs)}

Data collected on the triglycerides (TGs) levels of smokers before and after treatment with kalonji (Table 1) showed that the triyglycerides level before treatment ranged from 210 to 267 with a mean value of 245.75 $\mathrm{mg} / \mathrm{dL}$ and a low CV of $5.57 \%$. Treatment with kalonji for 15 days, it was reduced and ranged from 195 to 250 with a mean value of $226.70 \mathrm{mg} / \mathrm{dL}$ and a CV of $6.08 \%$. After treatment for 30 days, it was further reduced, and ranged from 177 to 227 with a mean value of 204.75 $\mathrm{mg} / \mathrm{dL}$ and a CV of $5.98 \%$.

Comparing the levels of triglycerides of smokers before and after treatment with kalonji using t-test of significance, it was observed that the triglycerides level was significantly reduced $(245.75 \mathrm{a}$ vs $226.70 \mathrm{~b}, \mathrm{t} .01=20.84)$ after 15 days of treatment with a reduction of about $8 \%$ over the level before treatment. In case of treatment continued for 30 days, it was further reduced significantly $(245.75$ a vs $204.55 b$, t. $01=31.77)$ with a reduction of about $17 \%$.

\section{Effects of Honey on the lipid profile of smokers}

Data collected on the effect of honey on the lipid profile of male smokers have summarized in Table 2.

Total Cholesterol (TC): The results of changes in TC level of the smokers as affected by honey (Table 2) showed that the TC level ranged from 210 to 260 with a mean value of 244.15 and a CV of $5.44 \%$ before treatment. Fifteen days after treatment with honey, the TC level ranged from 190 to 239 with a mean value of 221.70 and a CV of $5.95 \%$. After 30 days of treatment with honey, the TC level of smokers ranged from 180 to 231 with a mean value of 214.10 and a CV of $5.60 \%$ Comparing the TC levels of smokers before and after treatment with honey, the TC levels of smokers before treatment and 15 days after treatment differed significantly from each other $(244.15$ a vs $2231.70 \mathrm{~b}, \mathrm{t} .01=22.45)$ and after treatment the TC level was reduced by about $9 \%$. TC level of smokers 30 days after treatment with honey was further significantly reduced $(244.15$ a vs $214.10 \mathrm{~b}$ $.01=19.37$ ) and the decrease in TC level was about $12 \%$.

\section{Low Density Lipoproteins (LDL)}

Data on the level of LDL of smokers (Table 2) showed that before treatment, it ranged from 175 to 262 with 
a mean value of 233.35 and a CV of $12.87 \%$. After 15 days of treatment with honey, LDL of this group dropped down and ranged from 155 to 238 with a mean value of 206.95 and a CV of $13.22 \%$. After 30 days of treatment with honey, the LDL level of smokers was further reduced and ranged from 156 to 233 with a mean value of 207.75 and a CV of $12.26 \%$.

Comparison of LDL levels of smokers before treatment and 15 days after treatment with honey, it was observed that the LDL level was significantly reduced after treatment $(233.35 \mathrm{a}$ vs $206.95 \mathrm{~b}, \mathrm{t} .01=24.57)$ and decreased by about $11 \%$. After 30 days of treatment, the difference between LDL level before and after treatment was significant $(233.35 \mathrm{a}$ vs $207.75 \mathrm{~b}, \mathrm{t} .01=22.30)$ and $\mathrm{LDL}$ decreased by about $11 \%$. However, there was no difference between LDL after 15 and 30 days of treatment.

\section{High Density Lipoproteins (HDL)}

Data obtained on the HDL level of smokers (Table 2) showed that it ranged from 26 to 34 with a mean value of 31.10 and a CV of $8.49 \%$ before treatment with honey. The HDL level of smokers after 15 days of treatment with honey ranged from 35 to 41 with a mean of 37.15 and a CV of $4.66 \%$. The HDL level of smokers after 30 days of treatment with honey was further increased and varied from 405056 with a mean value of 45.80 and a CV of $11.42 \%$.

When mean values of HDL before and after 15 days of treatment with honey were compared using t-test of significance, it was found that the DHL level was increased significantly $(31.10 \mathrm{~b}$ vs $37.15 \mathrm{a}$, t. $.01=-16.52)$ with an increase of about $20 \%$. In case of comparing HDL level before and 30 days after treatment with honey, it was observed that the HDL level was increased significantly (31.10b vs $45.80 \mathrm{a}, \mathrm{t} .01=-12.15)$ with an increase of about $47 \%$.

\section{Triglycerides (TGs)}

Data collected on TG level of smokers before treatment with honey (Table 2) showed that the TG level ranged from 190 to 265 with a mean value of 236.10 and a CV of $9.62 \%$. TG measured 15 days after treatment with honey ranged from 169 to 240 with a mean value of 209.65 and a CV of $10.26 \%$. TG levels of smokers after 30 days of treatment with honey varied from 141 to 237 with a mean value of 168.00 and a CV of $13.52 \%$.

Comparing the TG levels of smokers before treatment and after 15 days of treatment with honey using t-test of significance, it was observed that the TG level was significantly reduced with treatment $(263.10 \mathrm{a}$ vs 209.65 , t. $01=33.93$ ) and the decrease was about $11 \%$. In case of TG level after 30 days of treatment, it was reduced significantly $(244.15 \mathrm{a}$ vs $168.00 \mathrm{~b}, \mathrm{t} .01=9.69)$ with a decrease of about $29 \%$.

\section{Effect of standard (Atorvastatin) on the lipid profile of smokers}

Data on the effects of this standard drug on the lipid profiles of smokers have been summarized in Table 3.

\section{Total cholesterol (TC)}

Data obtained on the changes in TC levels of smokers before and after treatment with the standard (Table 3) showed that the TC level of smokers ranged from 220 to 276 before treatment with a mean value of 225.95 $\mathrm{mg} / \mathrm{dL}$ and a CV of 5.58 percent. After 15 days of treatment, the TC level of this group varied from 190 to 248 with a mean value of $229.65 \mathrm{mg} / \mathrm{dL}$ and a CV of $6.26 \%$. In case of TC levels of smokers 30 days after treatment, it ranged from 175 to 229 with a mean value of $204.65 \mathrm{mg} / \mathrm{dL}$ and a CV of $6.42 \%$.

Comparing the TC levels of smokers before treatment with the standard after 15 days of treatment, using t-test of significance, it was observed that the TC level of smokers was significantly dropped $(2.55 .95$ a vs 229.65 b t.01 =46.76) with a decrease of about $10 \%$. In case of comparison of TC levels of smokers before treatment and 30 days after treatment, it was found that the TC level was further dropped after treatment with standard significantly (255. 95 a vs 204.65 b, t.01 $=34.75)$ with a decrease of about $20 \%$.

\section{Low Density Lipoproteins (LDL)}

Data on the levels of LDL of smokers as affected by the standard (Atorvastatin) before and after treatment (Table 3) revealed that the LDL levels ranged from 185 to 259 with a mean value of $229.40 \mathrm{mg} / \mathrm{dL}$ with a CV of $8.92 \%$. Regarding the LDL levels of smokers 15 days after treatment, it was observed that the range of LDL was from 165 to 245 with a mean value of $198.80 \mathrm{mg} / \mathrm{DL}$ and a CV of $13.38 \%$. LDL levels of smokers after 30 days of treatment with the standard, ranged from 150 to 230 with a mean value of $192.55 \mathrm{mg} / \mathrm{dL}$ and a CV of $14.21 \%$. It is worth noting that the variability in the LDL levels increased after treatment with the standard.

\section{Low Density Lipoproteins (LDL)}

Data on the levels of LDL of smokers as affected by the standard (Atorvastatin) before and after treatment (Table 3) revealed that the LDL levels ranged from 185 to 259 with a mean value of $229.40 \mathrm{mg} / \mathrm{dL}$ with a CV of $8.92 \%$. Regarding the LDL levels of smokers 15 days after treatment, it was observed that the range of LDL was from 165 to 245 with a mean value of $198.80 \mathrm{mg} / \mathrm{DL}$ 
and a CV of $13.38 \%$. LDL levels of smokers after 30 days of treatment with the standard, ranged from 150 to 230 with a mean value of $192.55 \mathrm{mg} / \mathrm{dL}$ and a CV of $14.21 \%$. It is worth noting that the variability in the LDL levels increased after treatment with the standard.

Comparing the LDL levels of smokers before treatment and 15 days after treatment, there was significant difference between the two levels (229.40 a vs $198.80 \mathrm{~b}$, t. $01=10.71)$ and the LDL was decreased by $13 \%$ after treatment. In case of 30 days after treatment with standard, the LDL level was further lowered significantly $(229.40$ a vs 192.55 b, t.01=6.36) with a decrease of about $16 \%$.

\section{High Density Lipoproteins (HDL)}

Data recorded on measured levels of HDL before and after treatment with standard (Table 3) revealed that the levels of HDL before treatment varied from 23 to 32 with a mean value of $26.70 \mathrm{mg} / \mathrm{dL}$ and a CV of $9.18 \%$. In case of HDL levels after 15 days of treatment with standard, it can be visualized that it ranged from 30 to 38 with a mean value of $35.15 \mathrm{mg} / \mathrm{dL}$ and a CV of $6.00 \%$. HDL levels 30 days after treatment with standard varied from 45 to 55 with a mean value of 49.55 $\mathrm{mg} / \mathrm{dL}$ and a CV of $5.65 \%$.

Comparing the HDL levels before and after 15 days of treatment with standard using t-test of significance, it was found that the HDL was increased significantly after treatment $(26.70 \mathrm{~b}$ vs $35.15 \mathrm{a}, \mathrm{t} .01=-12.00)$. With an increase of about $13 \%$. In case of treatment 30 days after treatment, the HDL level was further increased significantly $(26.70 \mathrm{~b}$ vs $49.55 \mathrm{a}, \mathrm{t} .01=-24.80)$ with an increase of about $86 \%$.

\section{Triglycerides (TGs)}

Looking upon the data recorded on the TGs levels of smokers before and after 30 days of treatment with the standard (Table 3), it can be seen that the TG levels before treatment were 235 to 276 with a mean value of $257.95 \mathrm{mg} / \mathrm{dL}$ and a CV of $3.54 \%$. Fifteen days after treatment with the standard, the TG levels were decreased ranging from 180 to 256 with a mean value of $226.45 \mathrm{mg} / \mathrm{dL}$ and a CV of $10.09 \%$. In case of treatment for 30 days, the TG level ranged from 170 to 240 with a mean value of $206.80 \mathrm{mg} / \mathrm{dL}$ and a CV of $11.16 \%$. However, it can be observed that the variability in the data on TG levels was increased.

Using t-test of significance, the TG levels of smokers before and after treatment with the standard were compared. It was found that the TG level was significantly lowered after 15 days of treatment as compared with the TG levels before treatment (257.95 a vs 226.45 b, t. $01=8.27)$ with a decrease of about $12 \%$. Looking at the levels of TG of smokers after 30 days of treatment, it was further lowered ( 255.95 a vs $206.80 \mathrm{~b}, \mathrm{t} .01=13.51)$ with a decrease of about $20 \%$.

\section{Comparative effect of different treatments on the lipid profile of smokers}

Data obtained on the effect of treatments on the lipid profile of smokers were analyzed statistically to compare the different treatments and summarized in Table 4. Data on the effect of kalonji (Nigella sativa), honey and the standard (Atorvastatin) on the TC of smokers (Table 4) after 15 as well as 30 days showed that the differences between the three treatments were found non-significant.

Means followed by similar letter(s) in each row do not differ significantly from one another at $\mathrm{P}<0.05$.

Similarly, the differences between the three treatments as regards their effect on LDL level of smokes were also non-significant for both after 15 and 30 days of treatments. In case of HDL levels after 15 as well as after 30 days, the differences among the three treatments were significant. By comparing the three treatments after 15 days of treatment, it can be seen (Table 4) that the honey increased the HDL level of smokers significantly over Atorvastatin but was at par with kalonji. Moreover, Atorvastatin was also comparable with kalonji. However, after 30 days of treatment, Atorvastatin significantly increased the HDL levels of smokers over honey and kalonji. Kalonji and honey also differed significantly from each other. The order of effectiveness was Atorvastatin $>$ honey $>$ kalonji.

As regards the TG levels of smokers, the results were significant. By comparing different treatments after 15 days of treatment on the TG levels of smokers (Table 4), it was found that honey reduced the TG levels significantly as compared with the other treatments, while kalonji and Atorvastatin were at par with each other. Similarly after 30 days of treatment, honey reduced the TG levels of smokers significantly as compared with the other two treatments. In return, kalonji and Atorvastatin were at per with each other.

Regression equations were developed to quantify the changes in the lipid profile parameters of smokers for different treatments (eq. 1-12). Comparing the b values i.e; slopes of the regression lines of different treatments for smokers, it was found that b-value (-1.78) for kalonji was the highest and the lowest (-1.00) for honey. In case of LDL, b-value (-1.46) was highest for kalonji and the lowest $(-0.76)$ for Atorvastatin. Regarding HDL, the highest b-value (1.71) was for Atorvastatin and the lowest (0.28) for kalonji. In case of TGs, the highest 


\begin{tabular}{|c|c|c|c|c|c|c|}
\hline Variable & $\mathbf{N}$ & Mean & SD & Minimum & Maximum & CV (\%) \\
\hline \multicolumn{7}{|c|}{ Before Treatment } \\
\hline Total Cholesterol & 20 & 259.50 & 26.28 & 213.00 & 291.00 & 10.13 \\
\hline LDL & 20 & 252.50 & 15.96 & 210.00 & 271.00 & 6.32 \\
\hline HDL & 20 & 30.75 & 1.55 & 28.00 & 33.00 & 5.04 \\
\hline Triglycerides & 20 & 245.75 & 13.65 & 210.00 & 267.00 & 5.57 \\
\hline \multicolumn{7}{|c|}{15 Days After Treatment } \\
\hline Total Cholesterol & 20 & 228.50 & 26.85 & 190.00 & 266.00 & 11.75 \\
\hline LDL & 20 & 229.35 & 16.66 & 188.00 & 251.00 & 7.26 \\
\hline HDL & 20 & 36.25 & 1.68 & 33.00 & 39.00 & 4.63 \\
\hline Triglycerides & 20 & 226.70 & 13.78 & 195.00 & 250.00 & 6.08 \\
\hline \multicolumn{7}{|c|}{30 Days After Treatment } \\
\hline Total Cholesterol & 20 & 206.15 & 25.37 & 167.00 & 244.00 & 12.31 \\
\hline LDL & 20 & 208.80 & 18.94 & 165.00 & 234.00 & 9.07 \\
\hline $\mathrm{HDL}$ & 20 & 39.05 & 1.10 & 37.00 & 41.00 & 2.82 \\
\hline Triglycerides & 20 & 204.55 & 12.24 & 177.00 & 227.00 & 5.98 \\
\hline
\end{tabular}

\begin{tabular}{|c|c|c|c|c|c|c|}
\hline Variable & $\mathbf{N}$ & Mean & SD & Minimum & Maximum & CV (\%) \\
\hline \multicolumn{7}{|c|}{ Before Treatment } \\
\hline Total Cholesterol & 20 & 244.15 & 13.29 & 210.00 & 260.00 & 5.44 \\
\hline LDL & 20 & 233.35 & 30.04 & 175.00 & 262.00 & 12.87 \\
\hline HDL & 20 & 31.10 & 2.63 & 26.00 & 34.00 & 8.49 \\
\hline Triglycerides & 20 & 236.10 & 22.71 & 190.00 & 265.00 & 9.62 \\
\hline \multicolumn{7}{|c|}{15 Days after Treatment } \\
\hline Total Cholesterol & 20 & 221.70 & 13.20 & 190.00 & 239.00 & 5.95 \\
\hline LDL & 20 & 206.95 & 27.35 & 155.00 & 238.00 & 13.22 \\
\hline HDL & 20 & 37.15 & 1.73 & 35.00 & 41.00 & 4.66 \\
\hline Triglycerides & 20 & 209.65 & 21.51 & 168.00 & 240.00 & 10.26 \\
\hline \multicolumn{7}{|c|}{30 Days After Treatment } \\
\hline Total Cholesterol & 20 & 214.10 & 12.00 & 180.00 & 231.00 & 5.60 \\
\hline LDL & 20 & 207.75 & 25.46 & 156.00 & 233.00 & 12.26 \\
\hline HDL & 20 & 45.80 & 5.23 & 40.00 & 56.00 & 11.42 \\
\hline Triglycerides & 20 & 168.00 & 22.72 & 141.00 & 237.00 & 13.52 \\
\hline
\end{tabular}

b-value $(-2.27)$ was recorded for honey and the lowest for kalonji (-1.00).

\section{Kalonji}

TC $=258.06-1.78 *$ day $\quad r^{2}=0.42 \quad$ eq. 1

LDL $=252.07-1.46^{*}$ day $\quad r^{2}=0.53 \quad$ eq. 2

$\mathrm{HDL}=31.20+0.28 *$ day $\quad \mathrm{r}^{2}=0.82 \quad$ eq. 3

$\mathrm{TG}=246.27-1.37 *$ day $\quad \mathrm{r}^{2}=0.63 \quad$ eq. 4

\section{Honey}

$\mathrm{TC}=241.68-1.00 *$ day $\mathrm{r}^{2}=0.42 \quad$ eq. 5

LDL $=228.82-0.85 *$ day $r^{2}=0.16 \quad$ eq. 6

$\mathrm{HDL}=30.67+0.49 *$ day $\quad \mathrm{r}^{2}=0.65$ eq. 7

TG $=238.63-2.27 *$ day $\quad r^{2}=0.53 \quad$ eq. 8

\section{Atorvastatin}

$\begin{array}{lll}\text { TC }=225.34-1.23 * \text { day } & r^{2}=0.70 & \text { eq. } 9 \\ \text { LDL }=25.71-0.76^{*} \text { day } & r^{2}=0.27 & \text { eq. } 10 \\ \text { HDL }=255.98+1.71 * \text { day } & r^{2}=0.92 & \text { eq. } 11 \\ \text { TG }=255.98-1.71 * \text { day } & r^{2}=0.54 & \text { eq. } 12\end{array}$

\section{DISCUSSION}

The present study was undertaken to determine the effects of Kalonji (Nigella sativa) and honey on the lipid profile of patients with byper lipidemia having habit of smoking in comparison with the standard drug of Atorvastatin. Hyper lipidemia is a major risk factor for 


\begin{tabular}{|c|c|c|c|c|c|c|}
\hline Variable & $\mathbf{N}$ & Mean & SD & Minimum & Maximum & CV (\%) \\
\hline \multicolumn{7}{|c|}{ Before Treatment } \\
\hline Total Cholesterol & 20 & 255.95 & 14.29 & 220.00 & 276.00 & 5.58 \\
\hline LDL & 20 & 229.40 & 20.47 & 185.00 & 259.00 & 8.92 \\
\hline HDL & 20 & 26.70 & 2.45 & 23.00 & 32.00 & 9.18 \\
\hline Triglycerides & 20 & 257.95 & 9.13 & 235.00 & 276.00 & 3.54 \\
\hline \multicolumn{7}{|c|}{15 Days after Treatment } \\
\hline Total Cholesterol & 20 & 229.65 & 14.37 & 190.00 & 248.00 & 6.26 \\
\hline LDL & 20 & 198.80 & 26.59 & 165.00 & 245.00 & 13.38 \\
\hline HDL & 20 & 35.15 & 2.11 & 30.00 & 38.00 & 6.00 \\
\hline Triglycerides & 20 & 226.45 & 22.84 & 180.00 & 256.00 & 10.09 \\
\hline \multicolumn{7}{|c|}{30 Days After Treatment } \\
\hline Total Cholesterol & 20 & 204.65 & 13.14 & 175.00 & 229.00 & 6.42 \\
\hline LDL & 20 & 192.55 & 27.37 & 150.00 & 230.00 & 14.21 \\
\hline $\mathrm{HDL}$ & 20 & 49.55 & 2.80 & 45.00 & 55.00 & 5.65 \\
\hline Triglycerides & 20 & 206.80 & 23.08 & 170.00 & 240.00 & 11.16 \\
\hline
\end{tabular}

\begin{tabular}{|c|c|c|c|}
\hline \multirow{2}{*}{ Table 4: Comparison of three treatments on the lipid profile of smokers } \\
\hline \multirow{2}{*}{ Variables } & Kalonji & Honey & Atorvastatin \\
\cline { 2 - 4 } & \multicolumn{3}{|c|}{15 Days After Treatment } \\
\hline Total Cholesterol & $228.50^{\mathrm{a}}$ & $221.70^{\mathrm{a}}$ & $229.65^{\mathrm{a}}$ \\
\hline LDL & $229.35^{\mathrm{a}}$ & $206.95^{\mathrm{a}}$ & $198.80^{\mathrm{a}}$ \\
\hline HDL & $36.25^{\mathrm{ab}}$ & $37.15^{\mathrm{a}}$ & $35.15^{\mathrm{b}}$ \\
\hline Triglycerides & $226.70^{\mathrm{a}}$ & $209.65^{\mathrm{b}}$ & $226.45^{\mathrm{a}}$ \\
\hline & & 30 Days After Treatment \\
\hline Total Cholesterol & $206.15^{\mathrm{a}}$ & $214.10^{\mathrm{a}}$ & $204.65^{\mathrm{a}}$ \\
\hline LDL & $208.80^{\mathrm{a}}$ & $207.75^{\mathrm{a}}$ & $192.55^{\mathrm{a}}$ \\
\hline HDL & $39.05^{\mathrm{c}}$ & $45.80^{\mathrm{b}}$ & $49.55^{\mathrm{a}}$ \\
\hline Triglycerides & $204.55^{\mathrm{a}}$ & $168.00^{\mathrm{b}}$ & $206.80^{\mathrm{a}}$ \\
\hline
\end{tabular}

coronary artery diseases, measures to reduce plasma cholesterol level will reduce the risk of this disease.

\section{Effect of Kalonji (Nigella sativa)}

Nigella sativa seeds are the common drug used in Ayurvedic system of medicine and Tibbe-Nabvi (Prophet's Medicine) throughout the world. The usefulness of Nigella sativa (kalonji) has been mentioned in various Ahadees-e-Nabvi. The Prophet (PBUH) said, "Hold on to the use of black seed for it has a remedy for every illness except death."

The results of the present study revealed that the use of kalonji for 15 days as well as 30 days reduced the total cholesterol (TC), LDL and triglycerides (TGs) significantly $(\mathrm{P}<0.01)$, whereas HDL was increased significantly $(\mathrm{P}<0.01)$. Reduction in $\mathrm{TC}, \mathrm{LDL}$ and TGs of smokers after 15 days of treatment was about 12 , 9 and $8 \%$, respectively, and by about 21,17 and $17 \%$, respectively, after 30 days of treatments, whereas, HDL levels were increased by about 18 and $27 \%$ after 15 days and 30 days of treatment, respectively.

As regards comparison of kalonji with Atorvastatin, the differences between the two on TC and LDL levels of smokers were non-significant after 15 as well 30 days of treatment. Kalonji was also comparable with the standard drug on HDL after 15 days of treatment, while significantly more effective $(\mathrm{P}<0.05)$ than Atorvastatin after 30 days of treatment. Effect of kalonji on TGs levels of smokers was at par with Atorvastatin, after 15 as well as 30 days of treatment. It can be visualized that kalonji was equally or more effective than Atorvastatin for the treatment of smokers with hyper lipidemia.

Results of the present study are in agreement with the findings of the studies conducted by,,$^{5-9,17-19,5}$ also reported that kalonji (N. sativa) decreased cholesterol by 
$14.58 \%$, LDL by $23 \%$, triglycerides by $15.16 \%$, whereas HDL was increased by $3.18 \%$ significantly $(\mathrm{P}<0.05)$ after six months. ${ }^{18}$ also reported the effective reduction of serum cholesterol by Baraka oil (oil of N. sativa) in hyper cholesterolemic patients. Age of patients was 40 to 70 years.

In another study made by. ${ }^{17}$ on the hypo lipidemic activity of Nigella sativa using $800 \mathrm{mg} / \mathrm{kg} \mathrm{N}$. sativa oil in rats orally for four weeks, it was shown that there was a significant decrease in TC, LDL and TGs and an elevation of serum HDL level. ${ }^{9}$

studied the effect of Nigella sativa (kalonji) on serum cholesterol of albino rats and showed significant decrease in serum LDL-C level and increase in HDL-C levels. ${ }^{8}$ also reported significant decrease in serum LDL-C level and increase in serum HDL-C levels of albino rats by N. sativa. ${ }^{6}$ observed the effectiveness of Nigella sativa in dyslipidemia at Agha Khan University, Karachi. In this study favorable impact of powdered Nigella sativa (kalonji) seed in capsule was noted on all variables.

In another study, kalonji was used as an effective herbal drug in maintaining lipid profile in normal states and also no adverse effects were observed in this study they noted change after four weeks of two spoons of kalonji powder per day. The change in total cholesterol, LDL-C and HDL-C was $8.83 \%, 17.41 \%$ and $11.94 \%$, respectively as compared to baseline levels.

In a recent study $\mathrm{by}^{7}$, it was found that the treatment with Nigella sativa $(1000 \mathrm{mg} / \mathrm{kg} /$ day) showed a significant change in the lipid profile of rats. It showed 48.4\% improvement (reduction) in total cholesterol levels, 70\% reduction in LDL-C, $25.3 \%$ reduction in triglycerides levels. Moreover, HDL-C levels of rats showed 53.5\% improvement after kalonji treatment.

The carbonyl fraction of the seed extract has got excellent choleretic activity as shown by. ${ }^{20}$ Thus the choleretic characteristics of Nigella sativa may affect the body total lipid concentration and help prevent atherosclerosis. The exact mechanism of action of Nigella sativa is not known, however, it has been proved that volatile oil of $N$. sativa has two main constituents i.e. nigellone and thymoquinone which play a key role in heart disease prevention. ${ }^{21-23}$

In conclusion, the present study show that there is a significant $(\mathrm{P}<0.01)$ decrease in TC, LDL, and TG, and significant increase of HDL by Nigella sativa.

\section{Effect of Honey}

The results obtained on the effect of honey on the lipid profile of hyper lipidemic patients with smoking habit showed that the use of honey for 15 as well as 30 days lowered TC, LDL and TGs of smokers significantly
$(\mathrm{P}<0.01)$, while HDL levels were elevated significantly $(\mathrm{P}<0.01)$. Reduction in TC, LDL and TG levels of smokers after 15 days was 9,11 and $11 \%$, respectively, and 12,11 and $29 \%$, respectively, after 30 days of treatment. HDL level of smokers was elevated by 20 and $47 \%$ after 15 and 30 days of treatment, respectively.

Regarding comparison of honey with Atorvastatin, the difference between the two treatments on TC and LDL levels of smokers was non-significant after 15 as well as 30 days of treatment. HDL level of smokers was improved significantly $(\mathrm{P}<0.05)$ by honey over Atorvastatin after 15 days while after 30 days of treatment the reverse was true. In case of TGs levels of smokers, honey reduced the TGs level significantly over Atorvastatin after 15 as well as 30 days of treatment.

The results of the present piece of research are supported by the findings of many research workers of the country as well as those of abroad regarding the effectiveness of honey on hyper lipidemic patients. ${ }^{13,24-27,24}$

studied the effect of natural honey on hyper lipidemic subjects and reported that honey consumed for 15 days decreased cholesterol by $8 \%$, LDL-C by $11 \%$ and TGs by $2 \%$. In another study by. ${ }^{13}$ on anti-hyper lipidemic effect of acacia honey, it was observed that acacia honey has an anti-hyper lipidemic effect against diet induced byper lipidemia in rats. The overall anti-hyper lipidemic effect of acacia honey is probably due to a concentration of free radicals by anti-oxidants flavonoids.

Natural honey has been used since long both in medical and domestic needs, ${ }^{28}$ however, most of the previous studies are focused on honey's effects against byper lipidemia and production of free radicals ${ }^{25,26}$ but only recently as an anti-oxidant. The fact that the anti-oxidants have several preventive effects against different diseases, such as cancer, coronary diseases, inflammatory, disorders, neurological degeneration, and aging led to research for food rich in anti-oxidants. Anti-oxidant activity of honey and scavenging of free radicals that demonstrated in some previous studies may play an important role in the protective effects of honey, ${ }^{29-31,30}$ reported that honey has the potential capability to serve as an important source of natural anti-oxidants in human nutrition.

Little is known about the individual components of honey that are responsible for its anti-oxidant activity. In an investigation made by, ${ }^{25}$ oral consumption of buckwheat honey $(1.5 \mathrm{~g} / \mathrm{kg})$ plasma total phenolic content and anti-oxidant activities increased. In another study by Rakhaet al., 2008, it was concluded that natural wild honey might cause its cardio-protective and therapeutic effects against adrenaline-induced cardiac and vasomotor dysfunction directly (via its high total anti-oxidant capacity and enzymatic and non-enzymatic anti-oxi- 
dants), besides its substantial quantities of mineral elements such as magnesium, sodium and chlorine, and/ or indirectly by stimulating release of nitric oxide from endothelium through the influence of vitamin $\mathrm{C} .{ }^{15} \mathrm{In}$ general, the anti-oxidant capacity of honey appeared to be a result of the combined activity of a wide range of compounds including phenolic, peptides, organic acids, enzymes, Maillard reaction products, and possibly other minor components. ${ }^{31}$ In addition, the Prophet $(\mathrm{PBUH})$ said. "Honey is a remedy for every illness of the body and the Qur'an is a remedy for all illness of the mind, therefore I recommend to you the both remedies, the Qur'an and honey. ${ }^{20}$

\section{CONCLUSION}

It can be concluded from the above discussion that honey is as effective as drugs like Atorvastatin for the treatments of byper lipidemia. Moreover, honey is cheaper than the drugs and is also useful for other diseases as well.

At the end it can be visualized that both Nigella sativa (kalongi) and honey proved as effective as drug or better than the drug in improving some parameters of lipid profile. In addition, their beneficial effects have been given in the Qur'an and narrations of the Prophet (PBUH). Moreover, N. sativa and honey does not have any adverse effects like statin drugs.

\section{ACKNOWLEDGEMENT}

The authors would like to thank Prof. Valdir de Andrade Braga, PhD Biotechnology Center, Federal University of Paraiba/BRAZIL, Campus I - João Pessoa- PB for his kind help in the preparation of this article.

\section{CONFLICT OF INTEREST}

The authors declare that there is no conflict of interest.

\section{REFERENCES}

1. Khan NI, Naz L, Mushtaq S, Rukh L, Ali S, Hussain Z. Ischemic stroke: prevalence of modifiable risk factors in male and female patients in Pakistan. Pak J Pharm Sci. 2009;22(1):62-7.

2. Dodani SR, Mistry A, Khwaji M, Farooqi, R, Qureshi K, Kazmi et al. Prevalence and awareness of risk factors and behaviors of coronary disease in urban population of Karachi, the largest city of Pakistan: a community survey. J Public Health. 2004;26(3):245-9.

3. Gilani $\mathrm{AH}$, Jabeen $\mathrm{Q}, \mathrm{MAU}$ Khan. A review of medicinal uses and pharmacological activities of Nigella sativa. Pak J Biol Sci. 2004;7(4):741-1.

4. Ramadan MF 2007. Natural value, functional properties and nutracential applications of black cumin (Nigella sativa): An overview. J Food Sci Technol. 2007;42(10):1208-18.

5. Tasawar Z, Z Siraj Ahmad N, MH Lashari. The effects of Nigella sativa (Kalonji) on lipid profile in patients with stable coronary disease in Multan, Pakistan. Pak J Nutr. 2011;10(2):162-7.
6. Qidwai W, Hamza HB, Gilani A. Effectiveness, safety and tolerability of powdered Nigella sativa (kalonji) seed in capsules on serum lipid levels, blood sugar, blood pressure and body weight in adults: Results of a randomized double-blind controlled trial. J Altern Complement Med. 2009;15(6):639-44.

7. Muneera K, Saeed MA, Naveed AK, Majeed A, Ali H. Efficiency of Nigella sativa (Kalonji) for the treatment of hyper lipidemia in Sprague Dawley rats. J Rawalpindi Med Coll. 2013;17(1):144-7.

8. Dahri AH, Chandio AM, Rahoo AA, Memon RA. Effect of Nigella sativa (kalonji) on serum cholesterol of albino rats. J Ayub Med Coll Abbottabad. 2005;17(2):72-4.

9. Buriro MA, Tayyab M, Ditta A. Nigella sativa (kalonji) effects on serum cholesterol of albino rats. Professional Med J. 2011;18(1):142-6.

10. Zulma A, Lulat A. Honey: A remedy rediscovered. J R Soc Med. 1989;82:3845 .

11. Choudhury M. Honey: Is it worth rubbing it in? J Russian Soc Med. 1999;92:663-4.

12. Oskoui TE, Shaseb E, Ghaffari S, Najafi M. Prolonged preconditioning with natural honey against mycocardial infarction injuries. Pak J Pharm Sci. 2013;26(4):681-6.

13. Adnan F, Sadiq M, Jehangir A. Anti-hyper lipidemic effect of Acacia honey (DesiKikar) in cholesterol-diet induced hyper lipidemia in rats. Biomedica. 2011;27(13):62-7.

14. Al-Waili N. Natural honey lowers plasma prostaglandin concentrations in normal individuals. J Med Food. 2003;6(2):129-33.

15. Bhatti AU, Awan MF, Bakhsh A. Soil sampling strategies for precision soil testing. Pak J Soil Sci. 1995;10:1-5.

16. Ott L. An Introduction to Statistical Methods and Data Analysis. $2^{\text {nd }}$ ed. USA: Duxbury Press Boston; 1984;775.

17. El-Dakhakhani M, Mady NL, Halim MA. Nigella sativa L. oil protects against induced hepatoxicity and improves serum lipid profile in rats. Arzneimittel Forschung. 2000;50(9):832-36.

18. Tissera MHA, Kumaranayaka KS, Serasinghe P. Effective reduction of serum cholesterol by Baraka oil (oil of Nigella sativa) 1997. Available from: URL: http://barakaoil.org/reductioncholesterol.php.

19. Bamosa AO, Ali BA, Sowayan SA. Effect of oral injestion of Nigella sativa seed on some blood parameters. Saudi Pharm J. 1997;5:126-9.

20. El-Dakhakhani M. Some pharmacological properties of some constituents of Nigella sativa seeds. Planta Med. 1982;1:426-8.

21. Gad AM, El-Dakhakhny M, Hassan MM. Studies on the chemical composition of Egyption Nigella sativa L. oil. Planta Med. 1963;11:134-8.

22. Babayan VK, Koottungal D, Halaby GA. Proximate analysis, fatty acid and amino acid composition of Nigella sativa L. seeds. J Food Sci. 1978;43(4):1315-19.

23. Abdel-Aal, ES M, Attia RS. Characterization of black cumin (Nigella sativa) seeds. Alex Sci Exch. 1993;14:483-6.

24. Al-Waili NS. Natural honey lowers plasma glucose, C-reactive protein, homo cystein, and blood lipids in healthy, diabetic and hyper lipidemic subjects: comparison with dextrose and sucrose. J Med Food. 2004;7(1):100-7.

25. Schramm DD, Karim M, Schraded HR, Holt RR, Cardetti M, et al. Honey with high levels of anti-oxidants can provide protection to healthy human subjects. J Agri Food Chem. 2003;51(6):1732-35.

26. Bahrami M, Ataie-Jafary A, Hasseini S, Ferouzanfar M, Rahmani S, Pajouhi M. et al. Effects of natural honey consumption in diabetic patients: An 8-week randomized trial. Int J Food Sci. 2008;2:1-9.

27. Rudling M. Lowering of LDL cholesterol prevents cardiovascular diseases. Lakartidningen. 2006;103(43):3278-82.

28. Ahmed AK, Hoekstra MJ, Hage JJ and Karim RB. Honey-medicated dressing: transformation of an ancient remedy into modern therapy. Ann Plast Surg. 2003;50(2):143-7.

29. Gheldof N, Wang XH and Engeseth NJ. Buckwheat honey increases serum anti-oxidant capacity in human. J Agri Food Chem. 2003;51(5):1500-05.

30. Zalibera M, Stasko A, Slebodova A, Jancovicova V, Cemakova T, Brezova A et al. Anti-oxidant and radical-scavanging activities of Salovak honeys-An electron paramagnetic resonance study. Food Chem. 2008;110(2):512-21.

31. Gheldof N, Wang $\mathrm{XH}$, Engeseth NJ. Identification and quantification of antioxidant components of honeys from various floral sources. J Agri Food Chem. 2002;50(21):5870-77. 